\title{
COVID-19, the Food System and the Circular Economy: Challenges and Opportunities
}

\author{
Fabio Giudice ${ }^{1}$, Rocco Caferra ${ }^{2}$ and Piergiuseppe Morone ${ }^{3, *(1)}$ \\ 1 Department of Law, Economics, Politics and Modern Languages, LUMSA University of Rome, \\ 00193 Rome, Italy; fabiogiudice@outlook.com \\ 2 Department of Economics, Management and Law, University of Bari, 70124 Bari, Italy; \\ rocco.caferra@gmail.com \\ 3 Bioeconomy in Transition Research Group (BiT-RG), University of Rome Unitelma Sapienza, \\ 00161 Rome, Italy \\ * Correspondence: piergiuseppe.morone@unitelmasapienza.it
}

Received: 4 August 2020; Accepted: 22 September 2020; Published: 25 September 2020

\begin{abstract}
This paper analyzes the causes and effects of the COVID-19 crisis, with a specific focus on the food system. Food consumption and production has not only been impacted by the crisis, but it may have also contributed to causing the pandemic. After providing a brief introductory framework, the paper presents the results of a pilot study on the link between COVID-19 and the food system, as indicated by the social media activity of selected European Union (EU) Twitter accounts, measured using an original "theme popularity" metric. Thereafter, a systematic review of the literature is proposed to identify the causes of the rise in popularity of a sustainable food system theme, the potential consequences of the COVID-19 crisis for the food system (targeting the production, consumption and waste disposal phases) and possible solutions, focusing on the circular economy. Challenges and opportunities for policymakers in the short and long term are discussed. A holistic approach is advocated, as the global food system is intimately connected with society and requires deep cooperation among nation states and economic actors.
\end{abstract}

Keywords: COVID-19; food system; circular economy; sustainability; EU; Twitter

\section{Introduction}

The COVID-19 pandemic has generated a huge economic crisis and exposed many of the fallacies of the current world economic system, including the food system [1]. The aim of this paper is twofold: first, it aims at identifying the rise and fall of specific narratives related to the food system during the pandemic by means of a content analysis of social media content. This analysis will show how issues associated with the food system gained centrality throughout the lockdown, raising questions regarding the (lack of) sustainability and resiliency of the food system. Subsequently, it will present the preliminary findings of a systematic literature review aimed at identifying possible solutions for improving the food system within the recent scholarly debate. These two objectives represent, in the authors' view, two faces of the same coin. By addressing them simultaneously, we seek to present a full picture of how discourse around the food system (in the context of the COVID-19 emergency) is being shaped and communicated in the interest of developing solutions.

Communication strategies are important, especially in social and political contexts, as they offer the possibility to introduce and attract attention to new problems. To this extent, the dissemination of information is crucial in tracking the path that society should follow, as well as raising public awareness of the importance of particular issues. Hence, it is important to investigate how experts and policymakers propose solutions and inform citizens about the food system. Their methods for doing 
so, as discussed in the current work, might influence subjects' attitudes, behaviors and beliefs about adopting more sustainable practices.

The present analysis starts by framing the sustainability issue against the contemporary backdrop of the health and economic crisis effected by COVID-19 (Section 2). As the pandemic is a contingent matter that has yet to unfold its deepest consequences, we will only seek to evaluate its possible economic repercussions. There are divergent opinions on this matter, but one certainty is that the crisis will leave a mark and question the global economic order, as never before. We will explore the deep causes of the pandemic and the connection between COVID-19 and the current food system, which has exposed the fallacies of the latter.

Subsequently, we will analyze the communication strategy adopted by particular social media accounts (Section 3). As mentioned, we will specifically investigate the dynamics of European Union (EU) communications related to the food system. Our social media content analysis will aim at assessing: (1) how the COVID-19 pandemic has re-shaped the EU's social media agenda with respect to the food system and the circular economy; and (2) how themes relating to the food system and the circular economy have evolved/co-evolved over the period of the pandemic and gained momentum amongst EU citizens. To this end, we will focus on Twitter posts, as these enable the re-construction of social networks, comprised of vertexes (i.e., people, institutions) and links (connections between accounts, people and institutions).

In Section 4, we will analyze possible solutions identified in the recent literature, placing particularly attention on how the European food system might be revolutionized by the introduction of circular economy principles, also in light of the COVID-19 crisis. We will focus on the potential for circular economy solutions to impact all three stages of the food system-production, consumption and waste disposal.

Finally, we will summarize the interconnections between COVID-19, the food system and the circular economy. While there remains much work to be done to facilitate the transition to a more sustainable food system, many instruments have already been set out for this purpose. Within the context of the current pandemic, a socio-economic and political international shift could ease the process towards achieving a more sustainable and circular food system.

\section{How COVID-19 Has Affected Our Lifestyles: The Main Picture}

In January 2020, a previously unknown virus (then named SARS-CoV-2) was identified in China. A few weeks later, an outbreak that would soon be defined by the WHO as a pandemic began to test the health care systems of both advanced and developing countries. Lockdown measures were enforced to slow the spread of the virus and the mortality of the infectious disease. As a result, people were forced to stay at home, with a significant impact on economic activity and daily lifestyles. Accordingly, a symmetric shock on both demand and supply unfolded, with consequences for the world economy.

The COVID-19 pandemic differs from many previous pandemics in its wide spread through many countries. While the outbreak started in China, the world's leading manufacturer, it soon spread across the world, significantly affecting the US, Japan, Germany, France and Italy—all G7 countries with a significant role in the world economy and global value chains [2]. The COVID-19 crisis is complex in many ways, and it will leave its mark not only on public health, but also on the globalized economy, as previously conceived. A recent study found that countries with higher levels of socio-economic globalization have been more severely exposed to the virus [3]. Indeed, as Baldwin and Di Mauro [2] point out, companies, individuals and governments are experiencing disruptions that may eventually lead to deglobalization, as companies are quickly learning the risks involved in global supply chains.

Moreover, as stated in Renzo et al. [4], COVID-19 represents a massive challenge for public health, since the forced isolation has generated noticeable changes in daily lifestyles [5]. In particular, following the main focus of this paper, such sudden lifestyle changes might have both positive and negative impacts on food consumption. Existing studies are controversial in this sense, since some studies—such as [4]—have found evidence of healthier lifestyles during the lockdown, while others 
have revealed problems emerging from unsafe lifestyles during quarantine [6]. The pandemic has also abruptly changed food consumption habits in the short term, and it remains to be seen whether these changes will persist over time. As for the immediate reaction to the crisis, when people first learned about the forced lockdown measures, they rushed to grocery stores to fill their pantries. In a report dated March 2020, the Institute of Services for the Agri-Food Market (ISMEA) showed that panic buying was people's first instinctive reaction [7]. Accordingly, global supermarket shelves emptied of key food items, such as pasta, rice, canned goods, flour, frozen foods and bottled water [8], raising questions about the overall sustainability and resilience of the food system.

As will be discussed in the following section, the impact of COVID-19 on the food system has been well reflected in the EU's social media discourse about the food system throughout the pandemic period.

\section{Evidence from Social Media: A Pilot Study}

In this pilot study, we detect the rise and fall of specific narratives related to the food system. On the one hand, by employing an open source dataset of Twitter posts (i.e., 'tweets') about COVID-19, we show the general increase in public attention related to food themes during the pandemic. On the other hand, we investigate how the EU has directed greater attention to the sustainability of the food system. Following a brief discussion of the role played by social networks in disseminating information (Section 3.1), we will introduce a metric of theme popularity (Section 3.2) and use this to analyze public interest (Section 3.3) in the food system and the emergence and dynamics of EU narratives around the food system (Section 3.4).

\subsection{How Social Networks Disseminate Information}

As discussed in several studies $[9,10]$, the information provided by the media is of fundamental importance for policymaking, as it signals which issues are gaining traction, which are falling out of favor, and which have been introduced as entirely new problems for the public to digest. During the Internet era, the birth of social media provided the opportunity-even in political contexts (see, e.g., Neuman et al. [11])—for information to be disseminated at a low cost [12]. Many studies on social media have focused on the growth in popularity of social media platforms during election seasons, by observing the communication of politicians and political parties [13]. Other studies have addressed the interaction and influence between political social media posts and the public [14], investigating how policy agendas are often settled as a result of the interrelation between interest groups. A complete review of how Twitter data have been exploited to analyze the public debate can be found in Korakakis et al. [15]. Interestingly, Gandy [12] focused on how political agendas are built and, as defined in their paper, the process by which the news determines what is publishable and the way in which elected officials shift issues on the policy agenda based on the media and, in turn, the public.

Different from traditional media data, Twitter data allow for the re-construction of social networks, comprised of vertexes (i.e., people, institutions) and links (connections between accounts, people and institutions). In particular, Twitter reveals the number of accounts observing the activity of a specific account (i.e., the latter's number of followers). Via this metric, one can identify the in-degree centrality [16] of an account, which can be exploited as a measure of user popularity. Using such data, studies have explored how central nodes influence behavior among followers (see, e.g., Chen et al. [17]). Beyond this, Twitter provides several tools for analyzing the accounts that disseminate information and the nature of that disseminated information.

As mentioned in the previous section, the COVID-19 pandemic has raised new challenges with respect to virtuous behavior and the transition to a more sustainable and resilient food system. On the one hand, it is worth analyzing the public's general increase in interest in this issue. On the other hand, it is also relevant to analyze how political actors set the tone for this issue via their social media communication by (i) communicating and disseminating information about actions, interests and 
progress relating to specific themes, and (ii) inducing their network of followers to pro-actively cooperate to achieve the proposed ends. While content analysis has been extensively used to analyze the ways in which actors influence public opinion on environmental themes [18,19], to the best of our knowledge, no prior study has performed a content analysis of social media to analyze themes relating to the food system.

It is common for political organizations to broadcast their interests and disseminate political information via Twitter. For instance, the EU owns and operates several Twitter accounts that deal with both general and specific themes. By observing online interactions with these accounts, it is possible to identify popularity levels relating to the accounts' communicated themes.

The empirical exercise engaged in here will provide a general overview of the possible growing interest in specific food themes during the COVID-19 outbreak, and if and how such themes-associated with select EU Twitter accounts-have demonstrated increased activity over this period. In particular, we will focus on the theme of food management, particularly with respect to the re-organization of the food management system to guarantee savings, security and safety.

\subsection{Metric of Theme Popularity}

In this subsection, we introduce our measure of theme popularity (p). Following Li et al. [20], we propose a measure of popularity based on the number of retweets. This measure may be considered a natural extension of the methodology proposed in Li et al. [20], which included a measure of tweet popularity based on the number of retweets per tweet. In particular, the authors introduced this measure to investigate the interplay between popularity and multimedia content; that is, to understand the public resonance and relevance of particular tweets. In our case, we extend the authors' approach by considering the total number of retweets per tweet pertaining to a specific theme. In this way, we move from measuring single tweet popularity to measuring broader theme popularity, collecting different messages on the same topic. However, we also consider individual tweets, in order to not overlook tweets dealing with a specific theme that do not have a positive number of retweets.

For example, let us consider a tweet vector at time $t, t w t$, of variable length $N$. Each element of $t w t$ is defined as twi,t and assumes a value of 1, indicating the presence of a tweet. Accordingly, $N=0$ defines a null vector and indicates the absence of a tweet at period $t$. As a proxy of popularity, we consider the number of retweets per post, rtwi,t. The number of retweets measures the increase (decrease) in popularity of a given tweet; hence, it is computed in addition to the presence of the tweet. In this way, the popularity of theme $j$ at time $t(p j, t)$ is represented by:

$$
p_{j, t}=\sum_{i}^{N} t w_{i j, t}\left(1+r t w_{i j, t}\right)
$$

Using this formula, it is possible to jointly identify (i) the presence of tweets on a given theme $j$ and (ii) the popularity of that theme. We may also observe the distribution of retweets per tweet, in order to analyze whether the dynamics of the virus might have affected the popularity of the theme at hand. In the following section, we provide an overview of the main descriptive statistics.

\subsection{Social Media Attention during COVID-19}

COVID-19 has attracted the attention of various advocacy groups, as well as media and political actors. Undoubtedly, the crisis is unprecedented, costing millions of lives and testing the social, health and economic systems of many countries. During this crisis, many fears have arisen, largely due to interruptions in the global supply chain. Among these, food shortages have been highly debated, as demonstrated by Laborde et al. in 2020 [21] suggesting the need to rethink global food supply chains. The topic has also been covered by various websites, which have discussed opportunities to create an environmentally friendly post-pandemic world, often framing the discourse in the perspective of the transition to a circular economy. 
In this section, we employ Kaggle data (https://www.kaggle.com/smid80/coronavirus-covid19tweets), comprised of tweets posted between 9 March and 30 April 2020. Drawing on the theme popularity metric $(\mathrm{p})$ introduced above, Figure 1 shows the growing interest in the topic of food security, as evidenced in Twitter hashtags as the virus spread. Hashtags allow users to apply dynamic, user-generated tagging that helps other users easily find messages relating to a specific theme. Data on worldwide daily COVID-19 cases were sourced by the European Center of Disease Prevention and Control.

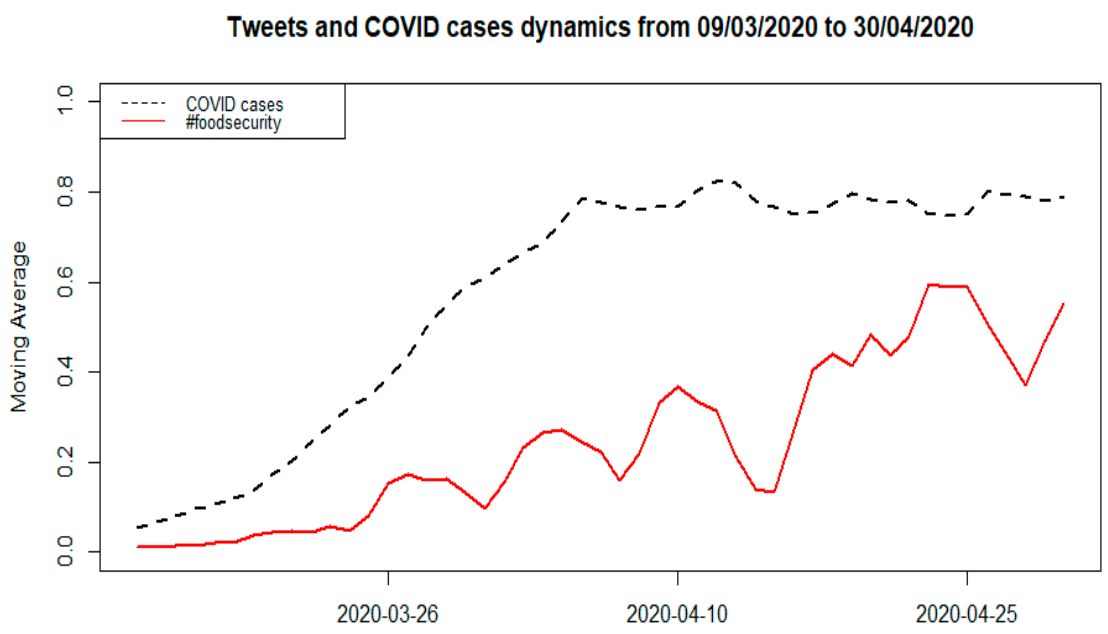

Figure 1. Distribution and dynamics of \#foodsecurity tweets and cases of COVID-19. Data were normalized and smoothed with a 5-day moving average. Maximum value $p=13,105$.

\subsection{EU Media Communication}

In this subsection, we introduce our analysis of the EU's social media agenda, as discussed at the beginning of this section. The official EU website devotes an entire section to the dissemination of information though social media. We selected the following six EU Twitter accounts for analysis (in brackets, we show the account ID and number of followers): (i) European Parliament (@Europarl_EN; 669,636), (ii) European Commission (@EU_Commission; 1,300,000), (iii) European Union Council (@EUCouncil; 507,691), (iv) European Food Safety Authority (@EFSA_EU; 35,831), (v) European Institute of Innovation \& Technology (@EITeu; 54,120) and (vi) European Economic and Social Committee Press (@EESC_PRESS1 5009). These accounts focus on general topics (as in the case of the European Parliament, European Council and European Commission accounts), as well as specific topics of innovation and development (as in the case of the European Food Safety Authority and European Institute of Innovation \& Technology accounts). We did not analyze out-of-topic accounts, since our proposed narrative did not apply to their social media content.

Here, we show the popularity of these accounts on the basis of their in-degree centrality, following $\mathrm{Li}$ et al. [20]. Figure 2 presents the in-degree distribution of the six accounts on a typical day of social media activity, identifying the level of centrality of the EU pages examined. Data refer to the \#covid19 hashtag (i.e., theme), and all analyses were conducted through the twitteR and rtweet packages in R, using a regular Twitter API. To provide a graphical overview, we plot the decumulative distribution function, whereby the $y$ axis presents the log rank of pages, ordered in ascending order from most to least (followers), and the $x$ axis presents the number of followers. Hence, the bottom right of the plot displays the most popular accounts (i.e., those with the highest number of in-degrees). As emerges from Figure 2, the EU accounts play a prominent role in disseminating information via social media. 


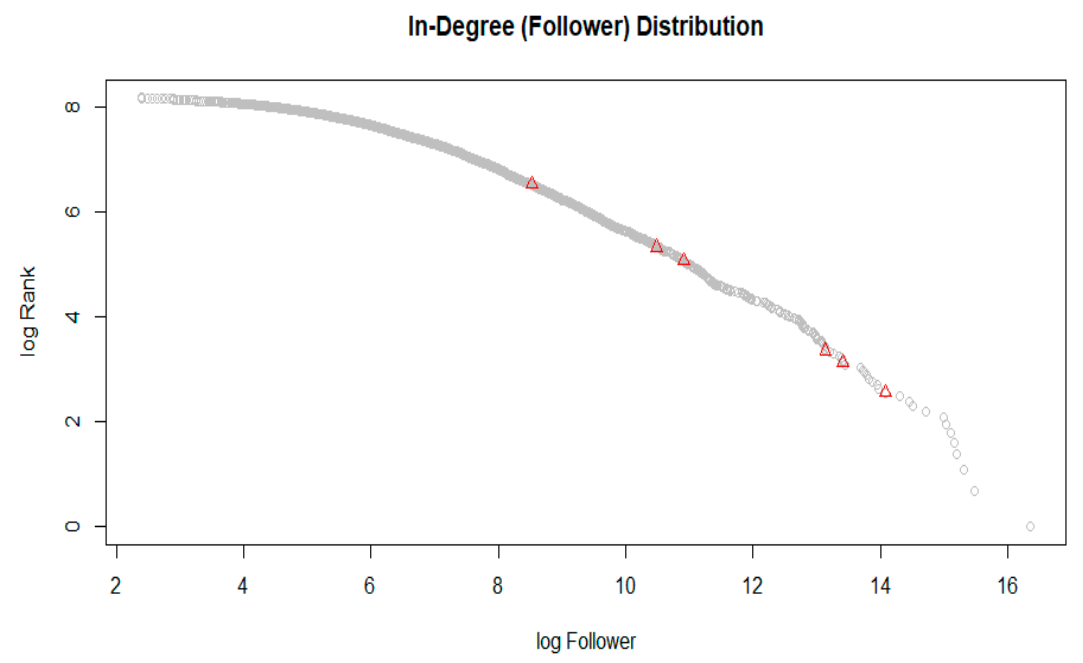

Figure 2. Account in-degree distribution, referring to social media activity on 26 June 2020 pertaining to the \#covid19 hashtag (theme). The data are comprised of 5000 tweets.

Moving onward, we track the timeline of account activity from 31 December 2019 to 26 June 2020. We consider the initial date in this period the day on which the first case of COVID-19 was detected. However, this date can be considered a pre-Covid stage in Europe, since the virus diffusion to Western societies is not thought to have begun until 11 March 2020. In particular, we are able to mine 534 tweets from the European Parliament account, 1862 from the European Commission account, 656 from the European Council account, 504 from the European Food Safety Agency account, 559 from the European Institute of Innovation \& Technology account and 655 from the European Economic and Social Committee account. From these tweets, we can observe the EU's stated position on food systems:

"The Green Deal is a key part of the EU's \#Covid19 recovery strategy for a greener, sustainable and inclusive Europe. Do you know what it tackles?" EU Parliament on Twitter, 2020-06-25

Thus, it seems that the EU's recovery communication strategy emphasizes the economic transition towards greater sustainability and resiliency.

In our mining exercise, we find 146 tweets relating to the food system. In order to find some important connections between the relevance and popularity of the food system and COVID-19, we split the sample into three timeframes:

- Pre-pandemic (pre): 1 January 2020 to 11 March 2020;

- Lockdown (during): from the WHO announcement of the pandemic (12 March 2020) to the partial relaxation of restrictive measures (30 April 2020);

- Post-lockdown (post): from 1 May 2020 to 1 July 2020.

As anticipated in Section 3.2, Table 1 provides a descriptive overview of the retweets distribution, distinguishing between the full sample (FS) (i.e., the initial set of mined tweets) and the sample of tweets pertaining to the food system (FSS). As is evident, the distribution of retweets for FSS was slightly lower than that of FS. However, it may also be noticed that FSS increased in popularity during the lockdown. 
Table 1. Descriptive statistics of the retweets distribution.

\begin{tabular}{ccccccccccc}
\hline \multirow{2}{*}{ Period } & \multicolumn{2}{c}{ Min rtw } & \multicolumn{2}{c}{ 1st Quartile } & \multicolumn{2}{c}{ Average rtw } & \multicolumn{2}{c}{ 3rd Quartile } & \multicolumn{2}{c}{ Max rtw } \\
\cline { 2 - 10 } & FS & FSS & FS & FSS & FS & FSS & FS & FSS & FS & FSS \\
\hline Pre & 0 & 2 & 8 & 6 & 91.83 & 46.48 & 96 & 26 & 1925 & 649 \\
During & 0 & 1 & 14 & 10.5 & 214.26 & 87.30 & 153 & 53.25 & 33,853 & 1043 \\
Post & 0 & 0 & 10 & 2 & 88.97 & 26.59 & 76.25 & 23.5 & 3299 & 246 \\
\hline \multicolumn{1}{c}{ FS = full sample; FSS = food system sample; rtw = retweets. }
\end{tabular}

By means of a manual content analysis, we can identify three main thematic areas:

- Food safety, defined as a measure of food health, ranging from the way it is produced to the way it is stored and consumed;

- Food security, defined as a measure of food availability and accessibility, including topics of food shortage, donation and wasting;

- Food sustainable management, defined as the system of incentives oriented towards guaranteeing the sustainability of the food supply chain.

The main results are presented in Figure 3. Here, we show the share of topic popularity, relative to the maximum possible popularity, over the reference period. To clarify, we consider the maximum share of popularity over the period as the sum of the respective total tweet popularities in the pre, during and post phases. In Figure 4, we illustrate the changes in discourse over time. It emerges that, in the pre phase, a large share of popularity was devoted to food safety themes. In line with the results shown in Figure 1, in the during phase, there was a marked interest in food security themes. Here, we found numerous tweets pertaining to food shortages and the importance of food donations, given the instability of the food system and the fear of not having enough supplies to meet basic needs. Tweets in the post period stressed the growing centrality of food sustainable management themes, stressing the importance of the development of an appropriate and sustainable food system in the post-pandemic world. As it seems, the resilience of the future economic system depends on the sustainability of its primary components. There is no question that the food system, which was under severe stress during the lockdown, is a crucial element of the system.

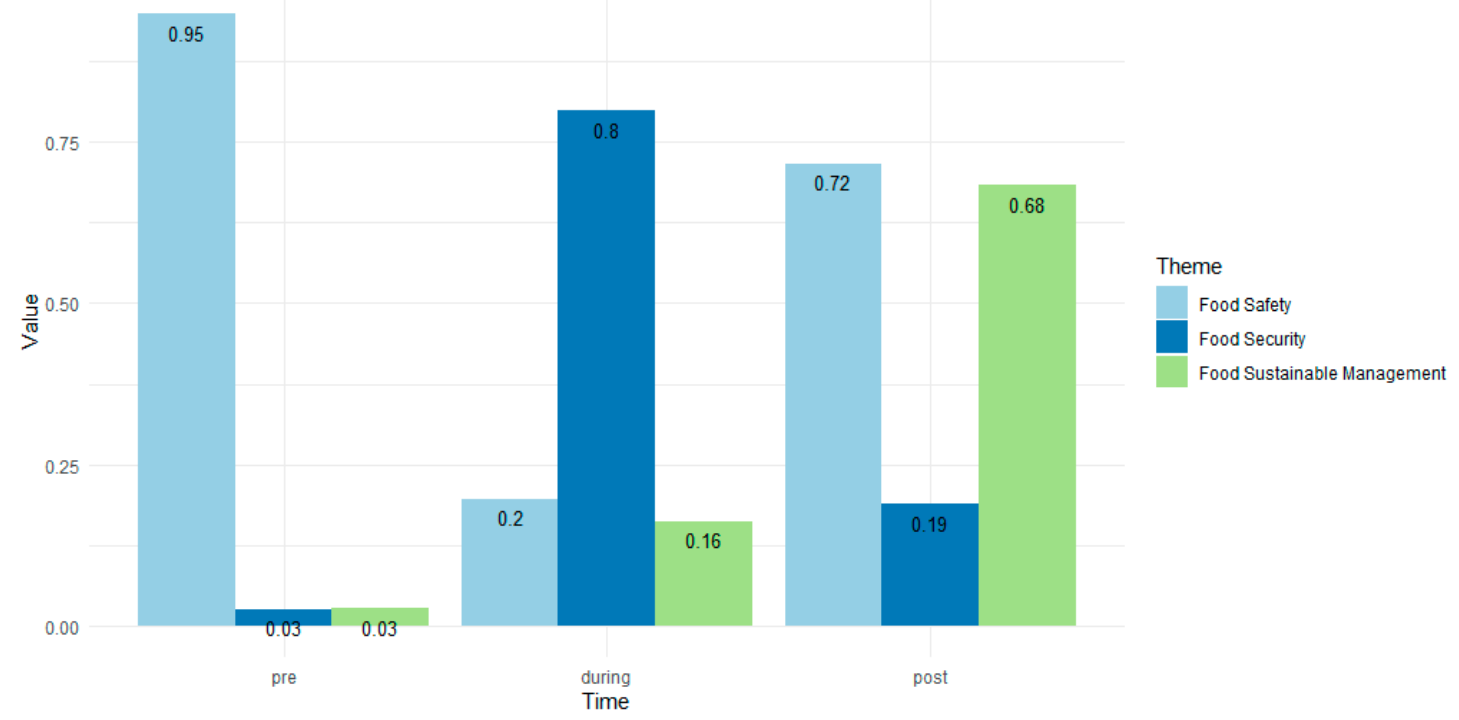

Figure 3. Popularity of EU tweet themes, normalized by the maximum value (1852 in the pre; 3179 in the during; 1959 in the post phase). 
Timeline of tweets- Some Examples

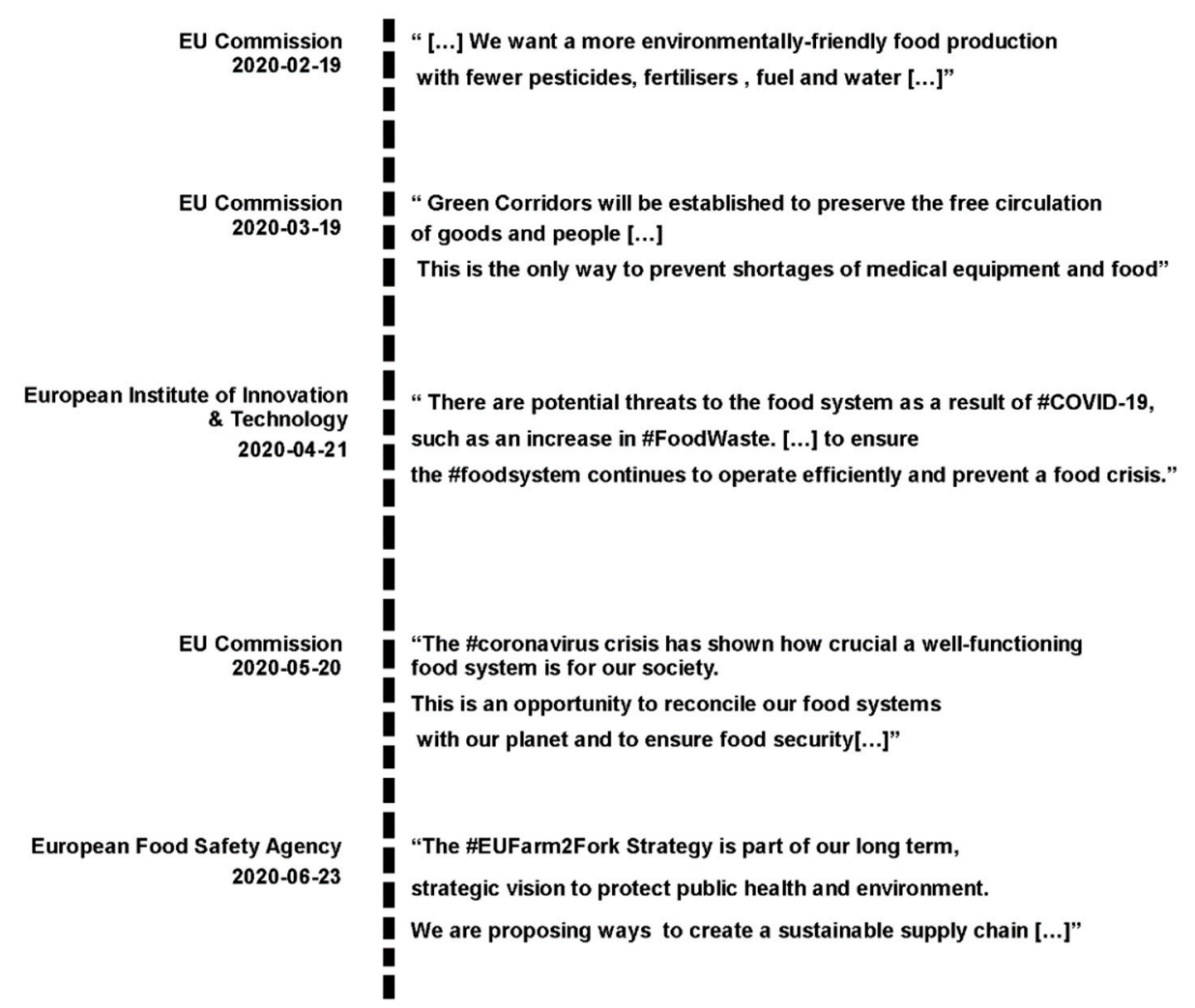

Figure 4. Timeline of example tweets showing the change in discourse over time.

Reflecting on these tweet patterns, it appears that the EU is suggesting that a green recovery must be at the center of the post-pandemic world. Focusing particularly on the food system, this is evident from the increase in popularity of the themes at hand. In our analysis, we consider the possibility that a tweet might simultaneously cover multiple topics; in such instances, we count the tweet towards different narratives on the basis of the precise topics covered. In particular, food safety and food sustainability are frequently jointly analyzed in the tweets, explaining the similar share of total popularity of these themes.

The EU effort towards achieving a sustainable food system began with the Farm2Fork (F2F) strategy, even before the spread of the virus. The F2F strategy is included in the European Green Deal set of actions aimed at mitigating climate change and related environmental disasters. The strategy focuses on the valorization of the food system, favoring the creation of a healthy and sustainable food environment. Indeed, as announced on the online EU portal of the F2F strategy:

"The COVID-19 pandemic has underlined the importance of a robust and resilient food system that functions in all circumstances, and is capable of ensuring access to a sufficient supply of affordable food for citizens $[\ldots]$ ]"

"Food systems cannot be resilient to crises such as the COVID-19 pandemic if they are not sustainable. We need to redesign our food systems $[\ldots$. ]"

This narrative is in line with the tone set by the EU on Twitter. Figure 4 presents a timeline of sample tweets. Such an illustration is standard in narrative analysis, as it is useful in guiding readers toward the main conclusion of the analysis [18]. Here, it is evident that the food system is not only a health issue, but also critical to the renaissance of the global economic system. As suggested by the example 
tweets in the post phase, COVID-19 has highlighted the importance of sustainable food management by revealing the food system as a pivotal aspect of the sustainable supply chain.

\section{COVID-19 and the Food System: Causes, Consequences and Circular Solutions}

Having shown the increased importance placed on the food system in the EU's social media agenda, as well as the growing concerns around the sustainability and resilience of the food system, we shall now discuss how this topic has been integrated into the scholarly and practitioner debate over the circular economy. By extending our analysis beyond social media, we hope to achieve a more finely grained assessment of the nexus between the COVID-19 pandemic and the food system. At the same time, by assessing the link between the food system and the circular economy, we seek to propose some actionable-albeit preliminary-solutions.

As the German philosopher Feuerbach said, "We are what we eat." Perhaps this saying might even extend to COVID-19, as many have pointed out that our global food system (and economy) greatly increases our risk of experiencing a pandemic. In what follows, we will present the results of our comprehensive systematic literature review (drawing on Tranfield et al.'s [22] approach) to assess causes, consequences and circular solutions pertaining to the link between the food system and the COVID-19 pandemic.

Systematic reviews differ from traditional narrative reviews in their replicable, scientific and transparent process, aimed at minimizing bias through exhaustive literature searches of published and unpublished studies and providing an audit trail of reviewers' decisions, procedures and conclusions. Our review began with the definition of our goals: to find and integrate the most recent and relevant literature on the relationship between COVID-19, the food system and the circular economy. Subsequently, we analyzed and selected the most recent available literature on the topic, encompassing both scientific papers and gray literature, such as reports and plans from policymakers and international organizations. No subjective distinction was made between scientific papers and other documents, provided that they respected the rules described hereinafter.

The research was mainly conducted through the SCOPUS and Google Scholar public search engines. Forty-three references were selected and shortlisted on the basis of publication date (published in 2015 or later) and correspondence with specific keywords (i.e., "COVID-19," "food," "circular economy"), with the aim of generating collective insights through a theoretical synthesis of fields and subfields. The search was first conducted with the use of the "AND" Boolean operator, then expanded using the "OR" Boolean operator.

The data extraction process focused on synthesizing key information, based on the abovementioned goal of offering an up-to-date review of the current global food system and selecting the most recent and relevant solutions to enhance its sustainability and circularity.

\subsection{Causes}

The World Food Programme [23] recently confirmed that the devastating economic impacts of COVID-19 reinforce the need for investments to prevent future outbreaks of infectious diseases. In so doing, it emphasized the interconnections between people, animals, plants and their shared environment, as well as the need for stable and sustainable architecture to make economic growth feasible, while respecting the surrounding environment [24,25].

There are two primary issues with the current industrial food system. First, intensive livestock production amplifies the risk of disease, since it involves the confinement of large numbers of animals in small spaces, narrowing genetic diversity and fast animal turnover. Second, habitat destruction, unchecked urbanization and land grabbing lead to amplified human-wildlife interaction, which eventually leads to zoonotic spillover [1]. It is therefore clear that pandemics, like the COVID-19 one, are not random events, but the logical result of our current food system and, to a wider scale, our economic model. 
Another catalyst of pandemics is urbanization, as indicated above. Thirty-five years ago, more than $60 \%$ of the global population lived in rural areas; this figure has now dropped to $46 \%$, while the urban population is set to reach $68 \%$ by 2050 [26]. Cities are already consuming $75 \%$ of the world's natural resources and $80 \%$ of the global energy supply [27]. Urbanization impacts food consumption patterns by increasing demand for processed foods, animal-based foods, fruits and vegetables. Higher urban wages also tend to increase the opportunity costs of preparing food and favor food products that require a large amount of labor, such as fast food, store-bought convenience food and food that is prepared and sold by street vendors [26].

China, the alleged epicenter of this and several previous disease outbreaks, has one of the highest urbanization rates in the world, having doubled its level over the past 40 years (from $22.7 \%$ to $54.4 \%$ ) [28]. This urbanization has closely paralleled rising animal protein consumption (due to higher wages), increased land conversion and livestock production, higher zoonotic risk (due to closer contact with wild animals) and a more rapid spread of pathogens through the globalized channels of world economy.

\subsection{Consequences}

As mentioned above, when lockdown measures were first introduced, stockpiling behaviors prevailed, while governments reassured their residents about the resilience of food supply chains and business continuity in the agri-food sectors. In fact, there are diverging opinions on the actual solidity of the current food system: for some, empty grocery shelves are not just the result of the human tendency to hoard in times of danger, but also an important reminder that our food supply chains are easily disrupted and that many of our food systems lack resiliency and redundancy [29]. Many global regions rely on highly centralized food systems, at the expense of strong local and regional systems that could provide a better buffering capacity when needed [29]. However, other scholars have countered that if the number of importing countries has risen for most crops, so has the number of exports in many countries. This has made trade more resilient to swings in supply and demand. Supply lines may empty, but alternatives can be found. For instance, when Indian traders stopped signing new export contracts in April, Carrefour, a French supermarket group, found new rice suppliers in Pakistan and Vietnam and opened a beef import route from Romania [30]. Nonetheless, even the most optimist commentators acknowledge that the current food system has bottlenecks (as does every global supply chain) and that good harvests in 2019 were able to account for some of the resilience of the food supply chain in the face of COVID-19 [30].

Over the long term, consumer food habits might change along three main directions. First, the rapid growth in online grocery delivery services might continue. While many big companies were already implementing this service pre-pandemic, their systems struggled to cope with the sudden expansion in online orders during the lockdown, leaving long time lags before delivery slots were available [8]. The same could be said about food delivery systems, which mainly operate via mobile phone apps: since the pandemic hit, such apps have been increasingly used by restaurants, as in-person dining has been severely restricted in many countries. Therefore, to some extent, the crisis has dematerialized and "desocialized" the food sector, speeding up consumers' adoption of online services. The duration and degree of this trend is still uncertain, but the effect could be noticeable (depending on cultural factors) [8].

Second, consumers might demonstrate a revived interest in "local" food supply chains. In fact, interest in "local foods" was established prior to the pandemic, as people understood this food to offer economic, social, environmental and health benefits [31]. Local food is usually perceived as fresher and-particularly in the present context-more convenient, as it can be easily bought in smaller stores, allowing consumers to avoid long queues outside supermarkets. During the pandemic, consumers also expressed a desire to support the economic recovery of local small and medium enterprises (SMEs). Again, how rooted and long-lasting this effect will be is still unknown, also considering that local food chains are less cost efficient than global ones [8]. 
Third, the pandemic has forced people to significantly change their daily lifestyles, and these changes might persist over the long term. Staying home all day in what was previously a rushed, globalized society has tested people's resilience and led them to question their priorities. People have been forced to slow down their rhythms and rediscover new hobbies and passions (e.g., cooking, instead of buying processed food). It seems that waste recycling has benefitted from these changes [32], alongside a general decrease in waste production (due also to the economic slowdown) [33].

\subsection{Circular Solutions}

As discussed above, the pandemic has put the current food system-focused on a linear and globalized production and consumption model-under high stress. Tjisse Stelpstra of the European Committee of the Regions has said that the devastating situation created by COVID-19 must bring all policymakers together and be the wake-up call for a new economic model that places social wellbeing and environmental sustainability at the core of the EU's economic recovery [33]. The circular economy could be a pivotal element of this recovery plan [34].

According to an EU advisory scientific study [35], achieving a sustainable food system means "increasing or maintaining agricultural yields and efficiency while decreasing the environmental burden on biodiversity, soils, water and air; reducing food loss and waste; and stimulating dietary changes towards healthier and less resource-intensive diets". Jurgilevich et al. [36] summarized that the EU Commission have identified three main stages of the food system with reference to the circular economy: production, consumption and waste.

As for the first stage, the "localization" of the food system might represent a more resilient and sustainable solution: localized food systems reduce waste and favor nutrients [36]. Combining local and seasonal elements in short supply chains reduces storage and transportation, provides a better supply-demand balance, creates more transparency and tracking and contributes to waste reduction. In addition, consumers seem to place higher value on food purchased in local markets.

Another known issue regarding food production is packaging. Our current food system is based on single-use packaging, although recent trends have shown improvements in both the quantity and the quality of this packaging. Still, many recycling processes are insufficient, as is the case for light PET bottles and multilayer plastic (as opposed to mono-material plastic) [37]. In this vein, policymakers should continue to incentivize the reduced use of plastic, in favor of more durable or recyclable materials, such as paper, aluminum, steel and glass, even though these materials do not altogether prevent the accumulation of unwanted metal ions through repeated recycling [37]. For this reason, research and development $(R \& D)$ in materials science and engineering must be a priority.

As for consumption, policymakers should focus on making sustainable choices the easiest options and transferring costs to unsustainable food choices. One example of a sustainable choice is the avoidance and/or reduction of meat consumption. Through the lens of the circular economy, reduced meat consumption increases the efficiency of material flows within the food system by reducing the amount of energy, land and water used per calorie of food produced [38]. Furthermore, policymakers should invest more in food and nutrition education, in order to raise awareness not only amongst the younger generations, but also amongst the older ones, by disseminating information campaigns through both traditional and innovative media channels.

Besides these non-binding actions, more incisive ones (i.e., fiscal and regulatory measures) could force producers and consumers to improve their practices in support of greater sustainability. Policymakers might introduce bans, impose specific production and sourcing requirements, influence demand via public procurement and impose taxes or fees. These fiscal measures might encourage producers, suppliers and retailers to make sustainable choices and/or directly add costs to unhealthy or non-sustainable food for customers, in the form of a Pigouvian tax. Indeed, the SAPEA report [39] states that "examples of relatively imposing instruments that have become increasingly popular include the use of fiscal instruments (e.g., sugar and fat taxes), standard-setting (e.g., on the maximum amount of salt allowed in products), and outright bans (e.g., on trans fats)" (p. 98). 
The final stage of the food system, relating to waste, is perhaps where the circular economy can have the largest and most immediate impact. Indeed, as stated by the European Union [35], "food waste takes place all along the value chain: during production and distribution, in shops, restaurants, catering facilities, and at home. This makes it particularly hard to quantify" [par 5.2]. Within the larger food system, production accounts for approximately $24-30 \%$ of total waste, while the post-harvest stage accounts for $20 \%$ and consumption accounts for $30-35 \%$. Cereals account for $53 \%$ of the total waste; surprisingly, meat accounts for only $7 \%$-far less than the impact of meat production on the environment [40]. According to Stuart, $30-50 \%$ of material intended for consumption (including animal material that is fed to animals or discarded as a byproduct) is wasted in North America and the EU at different stages of the food system [41]. According to Bajzelj [42], the reduction of food waste is essential for achieving a resilient food system.

It is important to distinguish between edible and non-edible food waste, as only the latter is actually defined as waste. Edible food is potentially ready to be consumed, either by its owner or by another person. To reduce food waste, food labelling policies should be changed and harmonized, as "best before" labels are likely to generate unnecessary waste due to consumer misperceptions of food quality. Indeed, according to Borrello et al. [43], "Even when consumers try to follow indications of producers, $20 \%$ of food is thrown away because of the confusion generated by the dates on product labelling". [p. 2]. Policymakers should act to prevent these losses by imposing strict limitations on "best before" labels. In this vein, the EU Commission announced that it "will examine ways of promoting a better use and understanding of date marking by the various actors of the food chain. The EU [35] has also adopted measures to prevent edible fish being thrown back into the sea from fishing vessels" [par. 5.2].

Some authors warn that food sharing initiatives might facilitate upstream food waste, as such initiatives allow consumers to get rid of their waste without preventing its generation in the first place. Thus, they act as "short-term sticking plasters" that obscure entrenched issues of food poverty. Further research is needed to verify the real impact of these actions, which are very diverse and fragmented in their nature [39].

As regards non-edible food waste, this should remain in the system chain and be regarded as a precious resource-not only for the production of more food, but also for the production of new energy (which can be used as fuel in countries seeking to reduce their environmental footprint) and much more. Some policymakers promote "backyard composting" [44], or self-composting at home. More actions and incentives may be needed to promote this activity, considering that it also facilitates the possibility of growing fruits, vegetables and other plants at home. This would enhance household engagement with the production of clean local food and reduce demand for industrial agricultural products, thereby limiting the use of water and chemical fertilizers.

That being said, food waste can take on many other forms, thanks to "green chemistry" solutions within bio-refineries, which can generate biofuels, bio-chemicals, plastics, textiles, medicines and more from organic waste [27]. While a circular food system should primarily aim at transforming food waste into new food, where this is not possible, the system should reinvest these resources into new energy or material forms, which may be equally socio-economically beneficial.

The present analysis clearly shows that a circular food system should not be entirely self-contained, but it should incorporate a wider reconsideration of the current fossil-fueled, linear and unsustainable economic model towards one that is green, resilient and sustainable model—that is, a bioeconomy powered by circularity. Policymakers should therefore engage more with this transition, with the aim of creating a fertile ground for a more sustainable food system (and society) by:

- Reshaping food production via localized supply chains and improved packaging;

- Guiding consumption towards sustainable choices, through a mixture of tax and education policies;

- Focusing and investing in the conversion of non-edible food waste into energy and materials, via green chemistry and bio-refineries. 


\section{Conclusions}

This paper addressed two fundamental issues: first, it outlined the connections between the food system and the current pandemic, investigating how COVID-19 has affected discourse around the food system; second, it matched the requirement for change in the food industry with circular economy solutions. As regards the first issue, we conducted an analysis of the EU's social media agenda, focusing on six institutional Twitter accounts. This allowed us to re-construct the social networks surrounding the food system discourse, identifying the number of users observing the activity of specific accounts and interpreting this as a measure of popularity of specific accounts/tweets. A key finding of this analysis was the change in popularity over time of three specific themes related to the food system: food safety, food security and food sustainable management. The analysis examined three subsequent time periods: the pre-pandemic period, the lockdown period and the post-lockdown period. As it emerged, the dominant theme in the pre-pandemic period was food safety; during the lookdown period, social media attention shifted to food security; finally, in the post-lockdown period, the theme of food sustainable management gained momentum. Far from being conclusive, these preliminary findings suggest how the shock of the pandemic first catalyzed social media attention around issues related to food shortages, donation and wasting (likely associated with the immediate fear of not finding food in stores), and subsequently developed into a deeper reflection on the overall sustainability (and resilience) of the current food system.

As regards the second issue-connecting the need for an alternative food system with circular economy solutions-we found that the circular economy, far from being a panacea, could be an important starting point by dismantling the take-make-dispose system that rules the current world economy. By means of a systematic literature review, we complemented our initial social media analysis with a more finely grained assessment of the emerging debate in the academic and policy literature, proposing ideas and solutions that can be implemented by policymakers and economic actors to improve the food system across all three of its phases (i.e., production, consumption, waste). As it seems, a profound and holistic discussion is emerging around the question of how sustainable the present food system is and how prepared it is to face the kind of shock posed by the COVID-19 pandemic. Circular practices seem to hold the potential for a win-win solution, simultaneously enhancing sustainability throughout the entire value chain (from production to consumption and post-consumption) and improving its resilience through the introduction of localized supply chains that minimize waste and further promote sustainable production and consumption.

The EU Commission is working in this direction, though it should accelerate the transition to new economic solutions, taking advantage of the COVID-19 crisis to make investments in greener technologies. In fact, much work remains to be done, especially on an international scale, where multilateral cooperation is needed more than ever yet is struggling under the influence of foreign policies. Only time will tell if the next pandemic will be met with a renewed spirit and vision, and perhaps a more sustainable food system.

Author Contributions: Conceptualization, P.M. and F.G.; methodology, F.G. and R.C.; software, R.C.; formal analysis, F.G. and R.C.; writing-original draft preparation, F.G. and R.C.; writing-review and editing, P.M.; supervision, P.M. All authors have read and agreed to the published version of the manuscript.

Funding: This research received no external funding.

Conflicts of Interest: The authors declare no conflict of interest.

\section{References}

1. FAO. COVID-19 and the Crisis in Food Systems: Symptoms, Causes, and Potential Solutions. Available online: http://www.fao.org/agroecology/database/detail/en/c/1271231/ (accessed on 11 September 2020).

2. Baldwin, R.; Weder, B.; Mauro, D. Economics in the Time of COVID-19. Available online: https://voxeu.org/ content/economics-time-covid-19 (accessed on 11 September 2020). 
3. Farzanegan, M.R.; Feizi, M.; Gholipour, H.F. Globalization and Outbreak of COVID-19: An Empirical Analysis; CESifo Working Paper Series; CESifo: Munich, Germany, 2020. [CrossRef]

4. Di Renzo, L.; Gualtieri, P.; Pivari, F.; Soldati, L.; Attinà, A.; Cinelli, G.; Cinelli, G.; Leggeri, C.; Caparello, G.; Barrea, L.; et al. Eating Habits and Lifestyle Changes during COVID-19 Lockdown: An Italian Survey. J. Transl. Med. 2020, 18, 229. [CrossRef] [PubMed]

5. De Carvalho, P.M.; Moreira, M.M.; de Oliveira, M.N.A.; Landim, J.M.M.; Neto, M.L.R. The Psychiatric Impact of the Novel Coronavirus Outbreak. Psychiatry Res. 2020, 286, 112902. [CrossRef] [PubMed]

6. Mattioli, A.V.; Sciomer, S.; Cocchi, C.; Maffei, S.; Gallina, S. Quarantine during COVID-19 Outbreak: Changes in Diet and Physical Activity Increase the Risk of Cardiovascular Disease. Nutr. Metab. Cardiovasc. Dis. 2020, 39, 1409-1417. [CrossRef] [PubMed]

7. Emergenza Covid 19: Pubblicato il Rapporto ISMEA Sulla Domanda e L'offerta dei Prodotti Alimentari Nelle Prime Settimane di Diffusione del Virus_ISMEA. Available online: http://www.ismea.it/flex/cm/pages/ ServeBLOB.php/L/IT/IDPagina/10990 (accessed on 3 September 2020).

8. Hobbs, J.E. Food Supply Chains during the COVID-19 Pandemic. Can. J. Agric. Econ. Rev. Can. D'agroeconomie 2020, 68, 171-176. [CrossRef]

9. Kiousis, S.; McCombs, M. Agenda-Setting Effects and Attitude Strength. Commun. Res. 2004, 31, 36-57. [CrossRef]

10. Shapiro, M.A.; Hemphill, L. Politicians and the Policy Agenda: Does Use of Twitter by the U.S. Congress Direct New York Times Content? Policy Internet 2017, 9, 109-132. [CrossRef]

11. Russell Neuman, W.; Guggenheim, L.; Mo Jang, S.; Bae, S.Y. The Dynamics of Public Attention: Agenda-Setting Theory Meets Big Data. J. Commun. 2014, 64, 193-214. [CrossRef]

12. Gandy, O.H., Jr. Beyond Agenda Setting: Information Subsidies and Public Policy; Ablex Publishing Corporation: New York, NY, USA, 1982.

13. Chi, F.; Yang, N. Twitter Adoption in Congress. Rev. Netw. Econ. 2011, 10. [CrossRef]

14. Boutyline, A.; Willer, R. The Social Structure of Political Echo Chambers: Variation in Ideological Homophily in Online Networks. Political Psychol. 2017, 38, 551-569. [CrossRef]

15. Korakakis, M.; Spyrou, E.; Mylonas, P. A Survey on Political Event Analysis in Twitter. In Proceedings of the 12th International Workshop on Semantic and Social Media Adaptation and Personalization, Bratislava, Slovakia, 9-10 July 2017; Institute of Electrical and Electronics Engineers Inc.: Piscataway, NJ, USA, 2017; pp. 14-19. [CrossRef]

16. Matei, S. Analyzing Social Media Networks with NodeXL: Insights from a Connected World by Derek Hansen, Ben Shneiderman, and Marc A. Smith. Int. J. Hum. Comput. Interact. 2011, 27, 405-408. [CrossRef]

17. Chen, Z.Y.; Fan, Z.P.; Sun, M. Individual-Level Social Influence Identification in Social Media: A LearningSimulation Coordinated Method. Eur. J. Oper. Res. 2019, 273, 1005-1015. [CrossRef]

18. Rosenbloom, D.; Berton, H.; Meadowcroft, J. Framing the Sun: A Discursive Approach to Understanding Multi-Dimensional Interactions within Socio-Technical Transitions through the Case of Solar Electricity in Ontario, Canada. Res. Policy 2016, 45, 1275-1290. [CrossRef]

19. Tani, A.; Morone, P. Policy Implications for the Clean Energy Transition: The Case of the Boston Area. Energies 2020, 13, 2615. [CrossRef]

20. Li, J.; Qi, G.; Zhao, D.; Nejdl, W.; Zheng, H.-T. Semantic Web and Web Science; Springer: New York, NY, USA, 2013. [CrossRef]

21. COVID-19 Risks to Global Food Security. Available online: https://reference.medscape.com/medline/abstract/ 32732407 (accessed on 3 September 2020).

22. Tranfield, D.; Denyer, D.; Smart, P. Towards a Methodology for Developing Evidence-Informed Management Knowledge by Means of Systematic Review. Br. J. Manag. 2003, 14, 207-222. [CrossRef]

23. Joint Statement on COVID-19 Impacts on Food Security and Nutrition/World Food Programme. Available online: https://www.wfp.org/news/joint-statement-covid-19-impacts-food-security-and-nutrition (accessed on 3 September 2020).

24. D'Adamo, I.; Falcone, P.M.; Martin, M.; Rosa, P. A Sustainable Revolution: Let's Go Sustainable to Get Our Globe Cleaner. Sustainability 2020, 12, 4387. [CrossRef]

25. D'Adamo, I.; Rosa, P. How Do You See Infrastructure? Green Energy to Provide Economic Growth after COVID-19. Sustainability 2020, 12, 4738. [CrossRef] 
26. Food and Agriculture Organization of the United Nations (FAO). The Future of Food and Agriculture. Available online: http://www.fao.org/publications/fofa/en/ (accessed on 11 September 2020).

27. Food, Cities and the Circular Economy. Available online: https://www.ellenmacarthurfoundation.org/ explore/food-cities-the-circular-economy (accessed on 3 September 2020).

28. Wu, T.; Perrings, C.; Kinzig, A.; Collins, J.P.; Minteer, B.A.; Daszak, P. Economic Growth, Urbanization, Globalization, and the Risks of Emerging Infectious Diseases in China: A Review. Ambio 2017, 46, 18-29. [CrossRef]

29. Five COVID-19 Reflections from a Food System Perspective-And How We Could Take Action-The Rockefeller Foundation. Available online: https://www.rockefellerfoundation.org/blog/five-covid-19reflections-from-a-food-system-perspective-and-how-we-could-take-action/ (accessed on 3 September 2020).

30. The Economist. A Dangerous Gap: The Markets v the Real Economy. 9 May 2020. Available online: https://www.economist.com/weeklyedition/2020-05-09 (accessed on 3 September 2020).

31. Cranfield, J.; Henson, S.; Blandon, J. The Effect of Attitudinal and Sociodemographic Factors on the Likelihood of Buying Locally Produced Food. Agribusiness 2012, 28, 205-221. [CrossRef]

32. Rifiuti a Roma, Meno $12 \%$ a Marzo Aumenta la Differenziata LA GUERRA AL COVID-19-Corriere.It. Available online: https://roma.corriere.it/notizie/cronaca/20_aprile_06/rifiuti-meno-12percentomarzoaumenta-differenziata-a281dccc-7760-11ea-9a9a-6cb2a51f0129.shtml (accessed on 3 September 2020).

33. Coronavirus in Lombardia, Meno 27.5\% di Rifiuti a Milano. Da Oggi Nuovo Ciclo di Sanificazione-La Repubblica. Available online: https://milano.repubblica.it/cronaca/2020/04/14/news/coronavirus_in_ lombardia_meno_27_5_di_rifiuti_a_milano_da_oggi_nuovo_ciclo_di_sanificazione-253954812/ (accessed on 3 September 2020).

34. D’Adamo, I. Adopting a Circular Economy: Current Practices and Future Perspectives. Soc. Sci. 2019, 8, 328. [CrossRef]

35. EU Commission. C. No. 98, 11th M. 2020, Para. 5. 2. EUR-Lex-52020DC0098-EN-EUR-Lex. Available online: https://eur-lex.europa.eu/legal-content/EN/TXT/?uri=COM:2020:98:FIN (accessed on 3 September 2020).

36. Jurgilevich, A.; Birge, T.; Kentala-Lehtonen, J.; Korhonen-Kurki, K.; Pietikäinen, J.; Saikku, L.; Schösler, H. Transition towards Circular Economy in the Food System. Sustainability 2016, 8, 69. [CrossRef]

37. Geueke, B.; Groh, K.; Muncke, J. Food Packaging in the Circular Economy: Overview of Chemical Safety Aspects for Commonly Used Materials. J. Clean. Prod. 2018, 193, 491-505. [CrossRef]

38. Mylan, J.; Holmes, H.; Paddock, J. Re-Introducing Consumption to the 'Circular Economy': A Sociotechnical Analysis of Domestic Food Provisioning. Sustainability 2016, 8, 794. [CrossRef]

39. SAPEA. A Sustainable Food System for the European Union. Available online: https://www.sapea.info/ topics/sustainable-food/ (accessed on 3 September 2020).

40. Vilariño, M.V.; Franco, C.; Quarrington, C. Food Loss and Waste Reduction as an Integral Part of a Circular Economy. Front. Environ. Sci. 2017, 5, 21. [CrossRef]

41. Stuart, T. Waste: Uncovering the Global Food Scandal; WW Norton \& Company: New York, NY, USA, 2009.

42. Bajželj, B.; Quested, T.E.; Röös, E.; Swannell, R.P.J. The Role of Reducing Food Waste for Resilient Food Systems. Ecosyst. Serv. 2020, 45, 101140. [CrossRef]

43. Borrello, M.; Caracciolo, F.; Lombardi, A.; Pascucci, S.; Cembalo, L. Consumers' Perspective on Circular Economy Strategy for Reducing Food Waste. Sustainability 2017, 9, 141. [CrossRef]

44. Illmer, P. Backyard Composting: General Considerations and a Case Study. In Microbiology of Composting; Springer: Berlin/Heidelberg, Germany, 2002; pp. 133-142. [CrossRef]

(C) 2020 by the authors. Licensee MDPI, Basel, Switzerland. This article is an open access article distributed under the terms and conditions of the Creative Commons Attribution (CC BY) license (http://creativecommons.org/licenses/by/4.0/). 